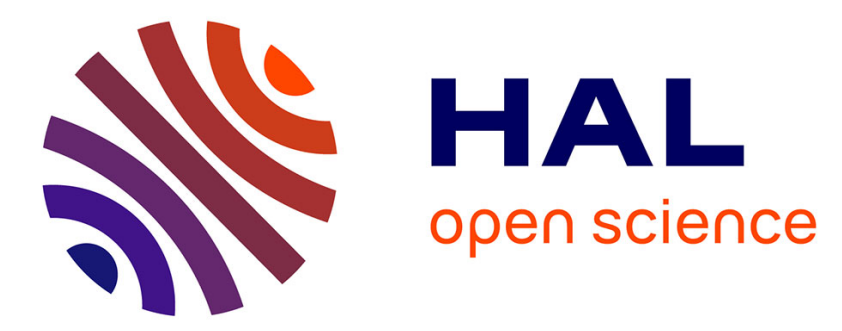

\title{
Solidification effects on sill formation: An experimental approach
}

Lola Chanceaux, Thierry Menand

\section{To cite this version:}

Lola Chanceaux, Thierry Menand. Solidification effects on sill formation: An experimental approach. Earth and Planetary Science Letters, 2014, 403, pp.79-88. 10.1016/j.epsl.2014.06.018 . hal-01131784

\author{
HAL Id: hal-01131784 \\ https://hal.science/hal-01131784
}

Submitted on 17 Mar 2015

HAL is a multi-disciplinary open access archive for the deposit and dissemination of scientific research documents, whether they are published or not. The documents may come from teaching and research institutions in France or abroad, or from public or private research centers.
L'archive ouverte pluridisciplinaire HAL, est destinée au dépôt et à la diffusion de documents scientifiques de niveau recherche, publiés ou non, émanant des établissements d'enseignement et de recherche français ou étrangers, des laboratoires publics ou privés. 

3 4 5

\title{
Solidification effects on sill formation: an experimental approach
}

\author{
L. Chanceaux ${ }^{\mathrm{a}, *}, \mathrm{~T}$. Menand $^{\mathrm{a}, \mathrm{b}, \mathrm{c}}$ \\ ${ }^{a}$ Université Blaise Pascal, Laboratoire Magmas et Volcans, F-63000 Clermont-Ferrand, France \\ ${ }^{b}$ CNRS, UMR 6524, LMV, Clermont-Ferrand, France \\ ${ }^{c}$ IRD, R 163, LMV, Clermont-Ferrand, France
}

\section{Abstract}

Sills represent a major mechanism for constructing continental Earth's crust because these intrusions can amalgamate and form magma reservoirs and plutons. As a result, numerous field, laboratory and numerical studies have investigated the conditions that lead to sill emplacement. However, all previous studies have neglected the potential effect magma solidification could have on sill formation. The effects of solidification on the formation of sills are studied and quantified with scaled analogue laboratory experiments. The experiments presented here involved the injection of hot vegetable oil (a magma analogue) which solidified during its propagation as a dyke in a colder and layered solid of gelatine (a host rock analogue). The gelatine solid had two layers of different stiffness, to create a priori favourable conditions to form sills. Several behaviours were observed depending on the injection temperature and the injection rate: no intrusions (extreme solidification effects), dykes stopping at the interface (high solidification effects), sills (moderate solidification effects), and dykes passing through the interface (low solidification effects). All these results can be explained quantitatively as a function of a dimensionless temperature $\theta$, which describes the experimental thermal conditions, and a dimensionless flux $\phi$, which describes their dynamical conditions. The experiments reveal that sills can only form within a restricted domain of the $(\theta, \phi)$ parameter space. These experiments demonstrate that contrary to isothermal experiments where cooling could not affect sill formation, the presence of an interface that would be a priori mechanically favourable is not a sufficient condition for sill formation; solidification effects restrict sill formation. The results are consistent with field observations and provide a means to explain why some dykes form sills when others do not under seemingly similar geological conditions.

\footnotetext{
${ }^{*}$ Corresponding author. E-mail address: l.chanceaux@opgc.univ-bpclermont.fr
} 
Keywords: sill formation, solidification, rigidity contrasts, analogue modelling

\section{\& 1. Introduction}

Sill intrusions are a major mechanism for constructing continental crust. Indeed, the amalgamation of repeated pulses of magma, many of them in the form of sills, can lead to the formation of magma reservoirs (John, 1988) and plutons as confirmed by geophysical data (Benn et al., 1999), theoretical models (Annen and Sparks, 2002; Menand, 2008), field studies and geochronological data (Miller et al., 2011; Horsman et al., 2010; Leuthold et al., 2012). Interconnected sill complexes have also been proposed as viable and efficient pathways for magma transport in the crust (Cartwright and Hansen, 2006; Muirhead et al., 2012). Thus sills could both lead to magma storage or its transport in the crust.

Different models of sill formation have been proposed based on field observations, laboratory experiments or numerical simulations: buoyancy could force sills to form at crustal levels where magmas become neutrally buoyant (Corry, 1988), or could help develop magma overpressures that are large enough to generate sills along specific horizons (Taisne and Jaupart, 2009); rigidity anisotropy in the crust could favour sill formation along those interfaces that separate an upper stiff layer from a softer lower one (Kavanagh et al., 2006; Burchardt, 2008; Maccaferri et al., 2010); rheology constrast between a ductile rock layer and a brittle one, or between adjacent layers where one is much more ductile than the other, would favour sill inception between these layers or within the weakest ductile zones (Parsons et al., 1992; Miller et al., 2011); and stress anisotropy would favour sill formations in crustal regions with high, horizontal, compressive deviatoric stress (Menand et al., 2010). An analysis of these different mechanisms suggests that crustal heterogeneities, and their mechanical or rheological anisotropies, would play a dominant role in controlling whether and where sills could form (Menand, 2011). However, all these studies have overlooked the potential effect of magma cooling and solidification.

All experimental and numerical studies on sill intrusions have therefore been carried out under isothermal conditions and have neglected the potential effect of magma solidification on sill for- 
mation and propagation. In fact, very few studies have dealt with cooling and solidification effects on intrusions. Theoretical studies (e.g. Bolchover and Lister, 1999; Lister, 1999) are limited to two dimensions, and so provide only a limited understanding of solidification effects because intrusions such as dykes and sills are inherently three-dimensional objects (e.g. Taisne and Tait, 2009, 2011). To our knowledge, Taisne and Tait (2011) are the only ones to have investigated experimentally solidification effects on intrusion propagation, focusing on dykes. They found that solidification effets have a strong impact on dyke dynamics: when solidification effects are important, dykes display an intermittent, stepwise mode of propagation, during which dykes momentarily stop propagating and then swell without advancing, before resuming their propagation when the incoming fluid that is stored in the fissure is able to fracture both the surrounding solid and the frozen crust that has developed within the fissure. Without solidification, dyke propagation operates continuously. Additionally, solidification affected the propagating dyke by focusing fluid flow in its central portion, hence limiting its horizontal dimension, and by adding a more complex geometry owing to the successive and intermittent outbreaks of fluid that occurred around the dyke periphery and sometimes away from its tip. These findings raise naturally the question of the effects that solidification could potentially have not only on the geometry and the dynamics of sills, but also on their formation.

To address this issue, we present laboratory experiments that involved the injection of hot vegetable oil (a magma analogue) which solidified during the propagation of an experimental dyke in a colder and layered solid gelatine (a host rock analogue). The gelatine solid had two layers of different stiffness, to create a priori favourable conditions to form sills. We investigated experimentally the effect of solidification on the formation of sills, and quantified how solidification can restrict sill formation. The exprimental approach is introduced in section 2, before presenting the experimental observations and results in section 3. We discuss their geological implications in section 4 and then conclude in section 5 . 


\section{Experimental approach}

\subsection{Experimental apparatus}

The experiments described here involved the injection of hot vegetable oil (magma analogue) in a colder gelatine solid inside a tank of $40 \times 40 \times 40 \mathrm{~cm}$ made of PMMA. The tank had circular openings of $1 \mathrm{~cm}$ diameter at its base to make injections (Fig. 1). The gelatine had two layers with different stiffness, the upper layer being stiffer than the lower one, to create a priori favourable conditions to form sills (Kavanagh et al., 2006). The solidification temperature of the vegetable oil is higher than that of gelatine, which allows the analogue intrusion to partially solidify during its propagation depending on injection conditions.

The injection temperature and the injection flux were controlled and varied between experiments in order to observe the effects of solidification on sill formation. The vegetable oil was heated with a bain-marie to the desired temperature. This temperature had to be higher than the solidification temperature of the vegetable oil, which is $31^{\circ} \mathrm{C}$ (Galland et al., 2006). The gelatine was first incised at the base of the tank through the injection point in order to obtain a preferred orientation for the development of a dyke (the incision was typically $5 \mathrm{~cm}$ high). The hot oil was then injected in the cold gelatine solid through a metal tube of $4 \mathrm{~mm}$ diameter that was inserted into the incision made, and connected to a pipe fed by a peristaltic pump. This pump allowed us to both control and maintain constant the volumetric injection flux $Q$ throughout each experiment. The temperature of the gelatine (host rock) and the injection temperature of the vegetable oil (magma), measured at the point of injection in the gelatine solid, were continuously recorded throughout the experiments with thermocouples while the experiments were recorded by a video camera in front of the tank.

\subsection{The gelatine}

The gelatine used is a 260 bloom, 20 mesh, pig-skin derived gelatine powder prepared in two batches to obtain a final solid with two layers of the same volume but different stiffness. The upper layer has to possess a higher stiffness than the lower layer, in order to create mechanically 
favourable conditions to form sills (Kavanagh et al., 2006). A higher gelatine concentration leads to a higher rigidity. The first batch of gelatine was poured in the tank, which was then placed in a fridge at a temperature of $\simeq 5^{\circ} \mathrm{C}$ for $\simeq 24$ hours. Once the gelatine was solid, the second batch was poured in the tank, which was then placed back in the fridge and kept at the same temperature for another $\simeq 72$ hours before running an experiment.

Before running an experiment, measurements of the elastic properties of the gelatine solid were performed. The Young's modulus was calculated by applying a cylindrical known-weight load on the upper layer of the solidified gelatine and measuring the deflection caused by this load. The measured deflection is directly linked to the Young's modulus $E_{u p p}$ of the upper layer (Timoshenko and Goodier, 1970):

$$
E_{u p p}=\frac{M g\left(1-\nu^{2}\right)}{D x}
$$

where $M$ is the mass of the applied load in $\mathrm{kg} ; g=9.81 \mathrm{~m} . \mathrm{s}^{-2}$ is the gravitational acceleration; $\nu=0.5$ is the Poisson's ratio of the gelatine (Crisp, 1952; Richards Jr and Mark, 1966); D is the diameter of the cylindrical load applied on the gelatine in $\mathrm{m} ; x$ is the deflection in $\mathrm{m}$; $E_{u p p}$ is the Young's modulus of the upper layer in $\mathrm{Pa}$.

To calculate the Young's modulus, the gelatine is assumed to be semi-infinite. To avoid base effects and side-wall effects when the load is applied on the gelatine in the tank, the diameter of the load needs to be $\leq 10 \%$ of the horizontal dimension of the tank (Kavanagh et al., 2013). In these experiments, the applied load measured $29.99 \mathrm{~mm}$ in diameter and so represented $7.5 \%$ of the tank size. The stress variation with depth induced by a load applied to the surface can also be calculated. According to Timoshenko and Goodier (1970), the largest stress component induced by a load $\sigma_{0}$ applied on top of a semi-infinite elastic body is the vertical component $\sigma_{z}$, which can be expressed as:

$$
\sigma_{z}=\sigma_{0}\left[1-\frac{8 z^{3}}{\left(1+4 z^{2}\right)^{\frac{3}{2}}}\right]
$$

where $z$ is the depth normalized by the load's diameter. The thickness of the gelatine layer was 100 
$\mathrm{mm}$, so $z=3.33$. Consequently, $\sigma_{z} / \sigma_{0}=3.3 \%$. The vertical stress generated by the surface load at $10 \mathrm{~cm}$ depth in a semi-infinite elastic medium would be only $3.3 \%$ of the surface load. This allowed us to assume that the base and side-wall had negligible effects, and to consider the upper gelatine layer as a semi-infinite medium, and equation (1) to be valid.

The formation of a sill requires that the Young's modulus of the upper layer $E_{\text {upp }}$ is higher than the Young's modulus of the lower layer $E_{l o w}$. It is not possible to directly measure $E_{l o w}$, but the Young's modulus ratio between the two layers can be easily calculated as a first approximation from the Youngs modulus ratio at infinite time, $\Delta E=E_{\text {upp }} / E_{\text {low }}$, provided the gelatine layers are left long enough to solidfiy. Indeed, the Young's modulus of the gelatine increases with time before reaching a plateau $E_{\infty}$ after about 48 hours, although the exact amount of time depends on the gelatine concentration and volume (Kavanagh et al., 2013). Therefore, the gelatine layers were left long enough before running an experiment to ensure they had reached their Young's modulus plateaus $E_{u p p \infty}$ and $E_{\text {low } \infty}$ (72 to 96 hours) and that the Young's modulus ratio had reached the constant value:

$$
\Delta E=\frac{E_{\text {upp } \infty}}{E_{\text {low } \infty}}=\frac{\alpha w_{\text {upp }}+\beta}{\alpha w_{\text {low }}+\beta}=\frac{w_{\text {upp }}-1.3}{w_{\text {low }}-1.3}
$$

where $w$ is the concentration by weight of the upper and lower layers; the numerical constants $\alpha$ and $\beta$ have been estimated to be $\alpha=6000$ and $\beta=-7800$ (Kavanagh et al., 2013). This ratio allows the value $E_{l o w}$ of the lower layer to be calculated once $E_{u p p}$ has been determined. This measurement method for the Young's modulus has the added advantage of ensuring that the time between the preparation of the two layers is kept to a minimum, which helps to create an interface between the two that is as strong as possible.

Our experiments were designed to investigate and quantify the potential effect fluid solidification could have on sill formation when mechanically favourable conditions are already met. As shown by Kavanagh et al. (2006) isothermal experiments, sills should always occur when the rigidity contrasts $\Delta E>1.1$. We therefore ran all our experiments in this mechanical condition and deliberately chose as narrow a $\Delta E$ range as possible to isolate and quantify the effect of solidifica- 
tion. The rigidity contrast $\Delta E$ in our experiments lied between 1.4 and 3.9.

\subsection{Experimental limitations}

Several assumptions were made in the experiments reported here. One limitation concerns a parameter that is unknown and uncontrolled in the experiments: the strength of the interface, i.e. how strongly welded the interface is. If an interface is weak or even not welded, it will necessarily force the creation of a sill, regardless of the rigidity contrast. This parameter will affect the formation of sills. In the experiments reported here, the interface is considered welded and relatively strong, but how strong is not known. This difficulty is inherent to an experimental approach, and quantifying the impact of interface strength on sill intrusions is more likely to be resolved by numerical studies.

Also, gelatine has an elastic behaviour and cannot act as an analogue material to simulate nonelastic behaviour of the crust. However, restricting our investigation to the elastic case, enabled us to focus on the effect solidification could have on sill formation, and to be able to compare our results with previous studies, which were also elastic. Moreover, even though rocks of the Earth's crust are fractured and heterogeneous, the elastic approximation has been shown to be appropriate to first order (Delaney and Pollard, 1981).

Finally, the state of stress is considered lithostatic (or "gelistatic"), so these experiments are not applicable to different stress environments (e.g. tectonic stresses, stresses induced by the load of a volcanic edifice, ...).

\subsection{Data processing}

To analyse the experiments, we follow the experimental analysis of Taisne and Tait (2011) and define two dimensionless parameters. One describes the thermal conditions of the experiments at the injection point (dimensionless temperature $\theta$ ) and the other describes their dynamical conditions (dimensionless flux $\phi$ ).

The dimensionless temperature $\theta$ is defined as:

$$
\theta=\frac{\left(T_{s}-T_{g}\right)}{\left(T_{i}-T_{g}\right)}
$$


where $T_{s}$ is the solidification temperature of vegetable oil, $T_{s}=31^{\circ} \mathrm{C}$ (Galland et al., 2006); $T_{g}$ is the gelatine temperature during the injection, typically between 5 and $7^{\circ} \mathrm{C} ; T_{i}$ is the injection temperature of vegetable oil. We note that $\theta$ can only be defined mathematically if the three temperatures differ from one another. This will not be the case if the injection temperature is equal to the gelatine ambient temperature as this would amount to having also the solidification temperature equal to the two other temperatures. In this particular case, trying to define a dimensionless temperature theta would therefore be meaningless.

The dimensionless flux $\phi$ is defined as the ratio between the heat advected by vegetable oil and the heat lost by conduction in the gelatine. $\phi$ describes the competition between the heat advected along the intrusion over a time $\Delta t$ to increase the temperature by an amount $\Delta T$ and the heat lost by conduction over a distance $\delta$ and the same time $\Delta t$. The advected heat $A$ is defined by $A=\rho H L B C_{p} \frac{\Delta T}{\Delta t}=Q \rho C_{p} \Delta T$ where $\rho$ is the density of the intrusion; $H$ is the thickness, $L$ the length, and $B$ the breadth of the intrusion; $C_{p}$ is the heat capacity of the intrusion; $Q=V / \Delta t$ is the flux, or volumetric rate of flow of the intrusion where $V=H L B$ is its volume. The heat lost by conduction $C$ is defined by $C=\rho H L B C_{p} \frac{\Delta T}{\Delta t}$ which diffuses over a distance $\delta$ in a time $\Delta t=\delta^{2} / \kappa$ where $\kappa$ is the thermal diffusivity. In the experiments presented here, the heat lost by conduction is considered to be over a distance similar to the thickness of the intrusion, i.e. $\delta \simeq H$. Therefore: $C=\frac{\rho H L B C_{p} \Delta T \kappa}{H^{2}}=\frac{\rho L B C_{p} \Delta T \kappa}{H}$. And we get the dimensionless flux:

$$
\phi=\frac{A}{C}=\frac{Q H}{\kappa L B}
$$

To find $H / L B$, a pressure balance is used (Taisne and Tait, 2011) between the buoyancy pressure $P_{b}$, that drives the intrusion, and the elastic pressure $P_{e}$, which allows the dyke to deform the host rock:

$$
P_{b}=P_{e} \Rightarrow \Delta \rho g L=\frac{E}{2\left(1-\nu^{2}\right)} \frac{H}{B} \Leftrightarrow \frac{H}{L B}=\frac{2\left(1-\nu^{2}\right)}{E} \Delta \rho g
$$

where $\Delta \rho$ is the density difference between the host rock and the intrusion; $g=9.81 \mathrm{~m} . \mathrm{s}^{-1}$ is the gravitational acceleration; $E$ and $\nu$ are the Young's modulus and the Poisson's ratio of the host rock. 


$$
\phi=\frac{3 Q \Delta \rho g}{2 E \kappa}
$$

where $Q$ is the flux of injection in $\mathrm{m}^{3} \cdot \mathrm{s}^{-1} ; \Delta \rho$ is the difference of density between the gelatine and the vegetable oil - from Galland et al. (2006), $\rho_{\text {vegetableoil }}=892 \mathrm{~kg} \cdot \mathrm{m}^{-3}$ and $\rho_{\text {gelatine }}=1000$ $\mathrm{kg} \cdot \mathrm{m}^{-3}$ (considered the same as that of water) therefore $\Delta \rho=108 \mathrm{~kg} \cdot \mathrm{m}^{-3} ; E$ is the Young's modulus of the lower layer (through which the dyke propagates); $\nu=0.5$ is the gelatine Poisson's ratio; $\kappa$ is the thermal diffusivity (assumed to be identical to that of water), $\kappa=1.4 \times 10^{-7} \mathrm{~m}^{2} \cdot \mathrm{s}^{-1}$; $g=9.81 \mathrm{~m} \cdot \mathrm{s}^{-2}$ is the gravitational acceleration.

$T_{s}$ and $T_{g}$ were essentially the same for all experiments so $\theta$ varied only with $T_{i}$ the injection temperature. Likewise, $\Delta \rho, g, \kappa$ were all kept constant. Consequently, $\phi$ varied between experiments with the injection flux $Q$ and the Young's modulus $E_{\text {low }}$ of the lower layer. $\theta$ and $\phi$ were maintained constant during an experiment ( $T_{i}, E_{\text {low }}$ and $Q$ were maintained constant), and were varied systematically betwen experiments to quantify their respective influence on the formation of sills.

$\theta$ varies between 0 and 1 and $\phi$ varies between 0 and $\infty$. Table 1 summarises the behaviour of $\theta$ and $\phi$.

\begin{tabular}{c|c|c}
$\theta \rightarrow 1$ & $T_{i} \rightarrow T_{s}$ & solidification operates rapidly \\
\hline$\theta \rightarrow 0$ & $T_{i}>>T_{s}$ & almost no solidification \\
\hline$\phi \rightarrow 0$ & low $Q$ values & solidification operates rapidly \\
\hline$\phi>>1$ & high $Q$ values & almost no solidification
\end{tabular}

Table 1: Behaviour of the dimensionless temperature $\theta$ and dimensionless flux $\phi$.

\subsection{Experimental strategy}

The flux $\phi$ and the temperature $\theta$ are dimensionless. These values are thus scale-independent, and can be compared between experiments and with values in nature. 
Regarding $\theta$, in the Earth's crust, values of $300^{\circ} \mathrm{C}$ at $\simeq 10 \mathrm{~km}$ depth and $450^{\circ} \mathrm{C}$ at $\simeq 15 \mathrm{~km}$ depth are obtained (using a thermal gradient of $30^{\circ} \mathrm{C} \cdot \mathrm{km}^{-1}$ ) for the temperature of the host rock $\left(T_{g}\right)$. Magmatic injection and solidification temperatures will depend on magma composition: for a basalt, reasonable values are $T_{i} \simeq 1200^{\circ} \mathrm{C}$ and $T_{s} \simeq 900^{\circ} \mathrm{C}$ while for a rhyolite, $T_{i} \simeq 800^{\circ} \mathrm{C}$ and $T_{s} \simeq 775^{\circ} \mathrm{C}$. Using equation (4), the range of natural values obtained for $\theta$ is:

- $\theta=0.67$ (basalt) to $\theta=0.95$ (rhyolite) at $10 \mathrm{~km}$ depth;

- $\theta=0.60$ (basalt) to $\theta=0.93$ (rhyolite) at $15 \mathrm{~km}$ depth.

Regarding $\phi$, Taisne and Tait (2011) used as natural values $E \simeq 10 \mathrm{GPa}, \kappa \simeq 10^{-6} \mathrm{~m}^{2} . \mathrm{s}^{-1}$ and $\Delta \rho \simeq 100 \mathrm{~kg} \cdot \mathrm{m}^{-3}$. The range of magmatic flux $Q$ is quite large, but values between 1 and 100 $\mathrm{m}^{3} \cdot \mathrm{s}^{-1}$ seem to be typical of many volcanoes, including Piton de la Fournaise Volcano, La Réunion Island, France (Traversa et al., 2010). Of course, these values could be extended. Indeed, magmatic fluxes can reach values higher than $1000 \mathrm{~m}^{3} . \mathrm{s}^{-1}$, i.e. an order of magnitude higher, as has been observed at the Mauna Loa in Hawaii or during the 1783 Laki eruption in Iceland (Macdonald and Finch, 1950; Thordarson and Self, 1993). However this is rather an exception, and values between 1 and $100 \mathrm{~m}^{3} \cdot \mathrm{s}^{-1}$ seem more reasonable. Using equation (7), the range of natural values obtained for $\phi$ is:

$$
\text { - } \phi=0.15\left(Q \simeq 1 \mathrm{~m}^{3} \cdot \mathrm{s}^{-1}\right) \text { to } \phi=16\left(Q \simeq 100 \mathrm{~m}^{3} \cdot \mathrm{s}^{-1}\right) \text {. }
$$

In order to scale experiments correctly, the range of experimental injection temperatures and fluxes were chosen to ensure they cover these ranges of natural values for $\theta$ and $\phi$. The experiments focused on the formation of sills in experiments involving solidification. Therefore $\theta$ and $\phi$ were varied systematically between experiments to identify whether these values affected conditions for the formation of sills and the type of the intrusions (feeder dykes or sills).

\subsection{Scaling}

If the experiments reported here represent a good analogue of natural intrusions, they should be correctly scaled so that their geometry, kinematics and dynamics are similar to those in nature. The 
scaling procedure for analogue intrusions defined in Kavanagh et al. (2013) is followed. Different scale ratios between experimental parameters and natural parameters are defined:

$$
L^{*}=\frac{L_{l}}{L_{n}} ; \quad T^{*}=\frac{T_{l}}{T_{n}} ; \quad U^{*}=\frac{U_{l}}{U_{n}} ; \quad E^{*}=\frac{E_{l}}{E_{n}}
$$

where the subscript $l$ means laboratory and the subscript ${ }_{n}$ means nature, so that ${ }^{*}$ is the ratio between the value measured in laboratory experiments and the natural value. $L$ is a length scale, $T$ is a time scale, $U$ is a velocity scale and $E$ is a Young's modulus scale.

The characteristic length scale of a dyke is the buoyancy length $L_{b}$ (Taisne and Tait, 2011). It is the length, for which the buoyancy pressure (allowing the ascent of the dyke) is balanced by resistance from rock fracture, and defined as:

$$
L_{b}=\left(\frac{K_{c}}{\Delta \rho g}\right)^{\frac{2}{3}}
$$

$K_{c}$ is the fracture toughness; $\Delta \rho$ is the density difference between the host rock and the fluid; $g=9.81 \mathrm{~m} \cdot \mathrm{s}^{-2}$ is the gravitational acceleration.

By introducing the reduced gravity scale $g^{\prime}=\Delta \rho / \rho_{\text {solid }}$ where $\rho_{\text {solid }}$ is the density of the host rock, a characteristic time scale $T$ and a characteristic velocity scale $U$ can be defined:

$$
T=\sqrt{\frac{L_{b}}{g^{\prime}}} \quad ; U=\frac{L_{b}}{T}
$$

To obtain a characteristic Young's modulus scale, a balance between the buoyancy pressure $\left(\Delta \rho g L_{b}\right)$ and the elastic pressure $\left(\frac{E}{2\left(1-\nu^{2}\right)} \frac{H}{L_{b}}\right)$ that occurs in the head region of the dyke is used, yielding the following scale:

$$
E=2\left(1-\nu^{2}\right) \Delta \rho g L_{b} \frac{L_{b}}{H}
$$

where $H$ is the thickness of the dyke head; $E$ is the Young's modulus of the surrounding solid, nd $\nu$ its the Poisson's ratio (Kavanagh et al., 2013). Moreover, $\nu=1 / 2$ for gelatine and $\nu=1 / 4$ 
$-1 / 3$ for rocks therefore $2\left(1-\nu^{2}\right)$ does not vary much between the laboratory and nature. From these expression we obtain:

$$
L^{*}=\left(\frac{K_{c}^{*}}{\Delta \rho^{*}}\right)^{\frac{2}{3}}
$$

$$
U^{*}=\left(\rho_{\text {solid }}^{*}\right)^{-\frac{1}{2}}\left(K_{c}^{*}\right)^{\frac{1}{3}}\left(\Delta \rho^{*}\right)^{\frac{1}{6}}
$$

$$
E^{*}=\Delta \rho^{*} L_{b}^{*}\left(\frac{L_{b}}{H}\right)^{*}
$$

In our experiments, $E_{l_{\text {mean }}} \simeq 5000 \mathrm{~Pa}$ implying a fracture toughness $K_{c} \simeq 100 \mathrm{~Pa} \cdot \mathrm{m}^{1 / 2}$ (Kavanagh et al., 2013). These values give us an experimental buoyancy length $L_{b} \simeq 22 \mathrm{~cm}$.

In nature, $K_{c}$ varies between $10^{6}$ to $10^{8} \mathrm{~Pa} \cdot \mathrm{m}^{1 / 2}$ depending on whether the value is measured in the field or in the laboratory (Delaney and Pollard, 1981). $K_{c} \simeq 10^{7} \mathrm{~Pa} \cdot \mathrm{m}^{1 / 2}$ seems to be a representative value. The ratio between thickness and length $H / L_{b}$ for a dyke varies in nature between $10^{-4}$ and $10^{-3}$ (Kavanagh and Sparks, 2011; Gudmundsson, 2011), while it is $\simeq 10^{-2}$ $10^{-1}$ in gelatine. The magnitude of $\Delta \rho$ in nature is $100 \mathrm{~kg} \cdot \mathrm{m}^{-3}$, i.e. the same as in gelatine. Finally, we take a value for $\rho_{\text {solid }}$ of $2800 \mathrm{~kg} \cdot \mathrm{m}^{-3}$ in nature and $1000 \mathrm{~kg} \cdot \mathrm{m}^{-3}$ in gelatine. Consequently:

- $L^{*}=4.6 \times 10^{-4}$

- $T^{*}=1.3 \times 10^{-2}$

- $U^{*}=3.6 \times 10^{-2}$

- $E^{*}=10^{-5}-10^{-7}$

With experimental values $L_{l}=L_{b} \simeq 22 \mathrm{~cm}, T_{l} \simeq 80-400 \mathrm{~s}, U_{l} \simeq 7 \mathrm{~mm} \cdot \mathrm{s}^{-1}$ and $E_{l}=E_{l_{\text {mean }}} \simeq$ $5000 \mathrm{~Pa}$, these give:

- $L_{n}=480 \mathrm{~m}$, which seems reasonable;

- $T_{n}=2-9 \mathrm{~h}$, which seems also reasonable; 
- $U_{n}=0.2 \mathrm{~m} \cdot \mathrm{s}^{-1}$, which is consistent with velocity of dykes between 0.1 and $0.5 \mathrm{~m} . \mathrm{s}^{-1}$ (White et al., 2011);

- $E_{n}=10^{9}-10^{11} \mathrm{~Pa}$, which are typical natural values.

These calculations confirm that the experiments are correctly scaled.

In addition to the scale ratios determined by Kavanagh et al. (2013), we define an additional characteristic dynamic flux scale. A natural flux scale is:

$$
Q=H L_{b} U
$$

and applying the same pressure balance between the buoyancy pressure and the elastic pressure in the dyke head region as before - equation (11) - yields the following expression for the thickness $H$ :

$$
H=\Delta \rho g\left(L_{b}\right)^{2} \frac{2\left(1-\nu^{2}\right)}{E}
$$

Consequently:

$$
Q^{*}=\Delta \rho^{*}\left(L^{*}\right)^{3}\left(E^{*}\right)^{-1} U^{*}
$$

$$
\Rightarrow Q^{*}=10^{-7}-10^{-5}
$$

Experimental fluxes $Q_{l}$ have typical values of $10^{-7}$ to $10^{-5} \mathrm{~m}^{3} \cdot \mathrm{s}^{-1}$, which would correspond to natural values $Q_{n}=0.01-100 \mathrm{~m}^{3} . \mathrm{s}^{-1}$, which are similar to natural values for volcanic systems (e.g. Traversa et al., 2010). We note that this range of natural flux $Q_{n}$ is deduced directly from a scaling argument and therefore it does not include any considerations of the thermal evolution of the intrusion. It is thus independent from the range of flux considered to calculate the range of dimensionless fluxes $\phi$ in section 2.5. The range of fluxes in the experiments thus correctly represent the dynamics of natural intrusions $\left(Q_{n}\right)$, and their thermal evolution $(\phi)$. 


\section{Results}

Fifteen experiments were performed with different injection temperatures and injection fluxes (Tab. 2). For each experiment, $\theta$ and $\phi$ were calculated. $\phi$ quantified the dyke dynamical conditions in the lower layer, and thus whether conditions for sill formation could be met.

\begin{tabular}{c|cccccc|cc|cc|cc} 
Exp & $w_{\text {upp }}$ & $w_{\text {low }}$ & $T_{g}(\mathrm{C})$ & $T_{i}(\mathrm{C})$ & $E(\mathrm{~Pa})$ & $Q\left(\mathrm{~m}^{3} \cdot \mathrm{s}^{-1}\right)$ & $\theta$ & $\phi$ & $\frac{\sigma_{\theta}}{\theta}$ & $\frac{\sigma_{\phi}}{\phi}$ & Result & Symbols \\
\hline 1 & 5 & 3 & 7.00 & 45.78 & 10164 & $1.38 \mathrm{E}-06$ & 0.62 & 1.54 & 0.03 & 0.08 & Sill & $\bullet$ \\
2 & 5 & 3 & 7.02 & 46.02 & 10164 & $2.50 \mathrm{E}-06$ & 0.62 & 2.79 & 0.03 & 0.07 & Crossing dyke & $\Delta$ \\
3 & 3 & 2 & 7.56 & 42.65 & 996 & $1.38 \mathrm{E}-06$ & 0.67 & 15.68 & 0.04 & 0.07 & Crossing dyke & $\Delta$ \\
4 & 3 & 2 & 5.73 & 44.08 & 3159 & $3.75 \mathrm{E}-06$ & 0.66 & 13.48 & 0.03 & 0.06 & Crossing dyke & $\Delta$ \\
5 & 4 & 2 & 5.87 & 38.35 & 2930 & $2.50 \mathrm{E}-06$ & 0.77 & 9.69 & 0.04 & 0.06 & Sill & $\bullet$ \\
6 & 4 & 2 & 6.24 & 34.81 & 2882 & $2.50 \mathrm{E}-06$ & 0.87 & 9.85 & 0.04 & 0.06 & Blocked dyke & $\square$ \\
7 & 4 & 2 & 6.24 & 34.81 & 2882 & $4.00 \mathrm{E}-06$ & 0.87 & 15.77 & 0.04 & 0.06 & Sill & $\bullet$ \\
8 & 4 & 2 & 6.64 & 32.44 & 1828 & $2.25 \mathrm{E}-06$ & 0.94 & 13.98 & 0.04 & 0.06 & Blocked dyke & $\square$ \\
9 & 4 & 2 & 6.64 & 32.44 & 1828 & $7.51 \mathrm{E}-07$ & 0.94 & 4.66 & 0.04 & 0.09 & No intrusion & $\star$ \\
10 & 5 & 4 & 6.66 & 37.72 & 12903 & $1.50 \mathrm{E}-05$ & 0.78 & 13.21 & 0.04 & 0.06 & Sill & $\bullet$ \\
11 & 5 & 4 & 6.66 & 37.72 & 12903 & $1.00 \mathrm{E}-06$ & 0.78 & 0.88 & 0.04 & 0.08 & No intrusion & $\star$ \\
12 & 4 & 2 & 6.57 & 43.34 & 3003 & $2.50 \mathrm{E}-06$ & 0.66 & 9.96 & 0.04 & 0.15 & Sill & $\bullet$ \\
13 & 4 & 2 & 6.57 & 43.34 & 2851 & $1.38 \mathrm{E}-06$ & 0.66 & 5.48 & 0.03 & 0.07 & Sill & $\bullet$ \\
14 & 4 & 2 & 6.57 & 40.89 & 2851 & $3.75 \mathrm{E}-07$ & 0.71 & 1.42 & 0.03 & 0.06 & Blocked dyke & $\square$ \\
15 & 4 & 2 & 6.48 & 37.07 & 3003 & $2.00 \mathrm{E}-06$ & 0.80 & 7.57 & 0.04 & 0.07 & Sill & $\bullet$
\end{tabular}

Table 2: Experimental data for investigation of sill formation.

$\theta$ is calculated from equation (4) with $T_{s}=31^{\circ}$ C. $\phi$ is calculated from equation (7) with $\Delta \rho=100, g=9.81 \mathrm{~m} . \mathrm{s}^{-1}$, $\kappa=1.4 \times 10^{-7} \mathrm{~m}^{2} \cdot \mathrm{s}^{-1} . E$ of the lower gelatine layer is determined and calculated from equation (3). The uncertainties $\sigma_{\theta}$ and $\sigma_{\phi}$ were calculated according to the principles of the "Propagation of Errors" (Bevington and Robinson, 2003).

In all experiments, a dyke was first generated in the lower layer. All experiments were prepared in such a way that the interface between the two gelatine layers was a priori mechanically favourable for the formation of sills ( $\Delta E>1.1$ - Kavanagh et al., 2006). However, contrary to what has been observed in previous isothermal experimental studies (e.g. Kavanagh et al., 2006), sill formation did not systematically occur. Instead, different types of intrusion were observed: 
dykes blocked at the interface, dykes passing through the interface, and sills. Each type of intrusion could be linked to distinct $\theta$ and $\phi$ fields.

\subsection{Types of intrusions}

The initial dyke could be blocked at the interface (Fig. 2A). It stopped its vertical propagation there and propagated laterally, underneath the interface, until the end of the injection (Fig. 3C). These dykes were particularly thick with a thickness to length ratio greater than $10^{-1}$.

When a sill formed (Fig. 2B) it took place at the interface between the two layers. Initially, the feeder dyke propagated in the same way as a dyke blocked at the interface before fracturing and propagating parallel to the interface, forming a sill (Fig. 3D). During the propagation of a sill, the upper layer was deformed and the interface bulged slightly towards the surface.

The dyke could also pass through the interface (Fig. 2C). It propagated initially in the same way as a dyke blocked at the interface before piercing the interface and propagating into the upper stiffer layer (Fig. 3E). The dyke made a pause before penetrating the interface and taking a triangular shape along strike above the interface. These dykes had a thickness to length ratio of $\simeq 10^{-1}$ (the length used is the total vertical length of the dyke in the lower and upper layer).

\subsection{Morphologies of intrusions}

Different morphologies of intrusions were observed, all similar to those observed in nature. The experimental dykes had sometimes a smooth surface, but were usually very irregular. Plumose structures were commonly observed (Fig. 4A). Additionally, many discontinuities could be seen at the leading edges of the experimental dykes as en-echelon segments (Fig. 4B) or lobes (Fig. 4C). These en-echelon segments did not always have the same orientation. The discontinuities observed on our experimental dykes are similar to those observed in Taisne and Tait (2011) and they are linked to solidification processes. We observe that for dykes and sills as solidification effects become more important, the number of discontinuities usually increases as well. Additionally, these discontinuities are not limited to the propagating tip of the fissure but are also initiated at the margins (e.g. Fig. 4C), which corroborates the observations of Taisne and Tait (2011). In 
comparison, the experimental sills had generally very smooth surfaces with few asperities filled with gelatine (Fig. 4D). The surface of the sills were smooth probably because they did not really need to fracture the gelatine in order to propagate along the interface. However, as for dykes, discontinuities were also observed at the edge of some (Fig. 4E).

\subsection{Result analysis}

The results of the experiments, that is blocked dykes, crossing dykes, sills and cases when fluid could not intrude the gelatine, are all summarised on a graph showing $\theta$ as a function of $\phi$ (Fig. 5). Solidification effects increase as $\theta \rightarrow 1$ and $\phi \rightarrow 0$. Four areas are clearly identified:

- when the dimensionless temperature is relatively high and the dimensionless flux is very low ( $\theta \simeq 0.75-0.95$ and $\phi<6$ ), there is no propagation (Fig. 5, stars). Solidification effects are so important that vegetable oil freezes and solidifies in the tube and no intrusion is observed;

- when the dimensionless temperature is high and for larger dimensionless fluxes $(\theta \simeq 0.7$ 0.95 and $\phi<15$ ), dykes are blocked at the interface between the two gelatine layers (Fig. 5 , squares). Solidification effects are important and the dyke partially solidifies at its walls during its propagation and development. Solidification at the upper tip of the dyke blocks its propagation, and prevent its piercing of the interface and subsequent propagation in the upper stiffer layer or its spreading along the interface as a sill;

- when the dimensionless temperature has intermediate values $(\theta \simeq 0.60-0.90$ and $\phi<16)$, sills are created (Fig. 5, disks). Solidification effects are smaller. Consequently, the feeder dyke propagates as a sill by spreading at the interface between the two layers;

- finally, when the dimensionless temperature is low $(\theta \simeq 0.60-0.70$ and $\phi>2)$, dykes passing through the interface are created (Fig. 5, triangles). Dykes do not create sills but instead pierce directly the interface to propagate in the upper layer, easily fracturing the gelatine presumably because of their high temperature: higher input of hot vegetable oil at the tip of the feeder dyke leads to lower solidification effects and presumably easier fracturation; 
the injection flux seemed to have less of an effect. However, solidification along the walls of the dyke seem to prevent the fluid from intruding the interface between the gelatine layers.

These results are consistent and systematic over the narrow range of rigidity contrasts $\Delta E$ used in the experiments $(1.4 \leq \Delta E \leq 3.9)$.

\section{Discussion}

\subsection{Sill Formation}

The first important result of our experiments is the difference with isothermal experiments (using water as the injected fluid) where there is no effect of solidification. Indeed, in these experiments (Kavanagh et al., 2006), sill formation occured systematically when the upper gelatine layer was stiffer than the lower one. With solidification effects, the rigidity contrast alone is not sufficient anymore to ensure sill formation. The conditions that are required for the formation of sills are reduced: it becomes more difficult to form sills when solidification of the flowing fluid occurs. At a given intermediate value of the dimensionless temperature $\theta$, dykes passing through the interface are created for higher values of the dimensionless flux $\phi$ whereas sills are created with lower $\phi$ values (i.e. lower injection flux $Q$ ). In the same way at a comparatively higher value of $\theta$, sills are created for higher values of $\phi$ and dykes blocked at the interface are created at $\phi$ comparatively lower $\phi$ values.

Each type of intrusion corresponds to a well defined area in Fig. 5, and so to a specific range of $\theta$ and $\phi$ values. The limits of each area appear well defined by the following linear relationships:

- (b): $\theta=0.019 \phi+0.68\left(\mathrm{R}^{2}=0.99\right)$;

- (c): $\theta=0.0039 \phi+0.61\left(\mathrm{R}^{2}=0.89\right)$.

These two equations (b) and (c) delimit the upper and lower ranges, respectively, of thermal $(\theta)$ and dynamical $(\phi)$ conditions for the formation of sills. It seems that there is also a separation between the "no propagation" area and the "dyke blocked at the interface" area (dashed line on Fig. 5), 
but this separation (a) is only qualitative. Sill formation depends on the thermal and dynamical conditions of the injected fluid. The thermal conditions $(\theta)$ depends essentially on the injection temperature $T_{i}$ whereas the dynamical conditions $(\phi)$ depends not only on the injection flux $Q$ but also on the rigidity of the intruded solid. Therefore, the formation of sills in our experiments depends mainly on three parameters: the rigidity of the rocks intruded below a potential interface, the injection temperature $T_{i}$, and the injection flux $Q$.

\subsection{Geological Applications}

These experiments were carried out under dimensionless conditions $(\theta$ and $\phi)$ identical to those present in nature. The experimental results can therefore be extended to natural conditions. These results imply that because of solidification effects, even if mechanical conditions are favourable (upper layer stiffer than the lower one), above some injection magmatic flux (equation (c), Fig. 5), sills are no longer created, and dykes passing through the interface are expected instead, which could lead to an eruption.

The experimental results provide also a means to explain why some dykes form sills when other dykes do not under seemingly similar geological conditions. If one considers a dyke that encounters an interface with favourable mechanical conditions (rigidity contrast with $\Delta E>1.1$ ), different scenarios can be envisaged depending on its dynamical and thermal conditions (Fig. 5). If conditions for sill formation were met (favourable injection temperature and flux), a sill would be created. However, a recharge in magma (e.g. the arrival of a new magma batch) or a new dyke propagating with a higher flux would change the dynamical and thermal conditions owing to increased magmatic flux and/or injection temperature. The conditions for sill formation would no longer be met and the dykes would now be able to cross the interface. In the same way, if a dyke was blocked at an interface because conditions for sill formation were not met (too low injection temperature or flux) a sill could subsequently form because of a recharge in magma, which would lead to a temperature and flux increase. Similarly, if a dyke crossed the interface because of a large injection temperature or flux, this dyke could later turn into a sill along a subsequent favourable mechanical interface. As magma flows, it cools down and its injection flux will likely decrease as 
magma is withdrawn from the source: thermal and dynamical conditions will change and increase the likelihood for sill formation further away.

These results are consistent with field observations. Indeed, sills are not created each time there is a suitable rigidity contrast (upper layer stiffer than the lower one) as illustrated in Fig. 6 where a feeder dyke crosses several interfaces in the same rock unit, and thus characterised by presumably similar rigidity contrast, before spreading as a sill at one of them. Solidification effects could be a plausible explanation for this behaviour.

Our experiments explored a limited range of dimensionless fluxes $\phi$ when extremely-high-flux dykes do sometimes occur in nature, with $\phi$ values perhaps as high as 200. Extrapolating the results summarised in Fig. 5 to high values suggests that dykes with extremely-high dimensionless flux would have a greater propensity for crossing interfaces and thus for getting closer to the surface. Although this makes sense, our results might not necessarily hold for such extreme events, and additional work should clarify the behaviour of these extremely-high-flux dykes.

Additionally, some issues could not be addressed with our experiments. First, these experiments assume the deformation of the host rock is elastic. If materials are not consolidated (pyroclastic flows, hyaloclastites, shales, ...), deformation can be ductile, which would affect the formation of sills (very weak interface because of very soft material, premature arrest of the feeder dyke ...). These interactions with non-elastic materials are expected to be more important for intrusions close to the surface because crustal heterogeneities are likely to be more important there.

Another issue is that these experiments study the effects of solidification on the magma but neglect the potential effect on the host rocks. The temperature difference between the host rock and the intrusion and the heat advected by the intrusion during its propagation may affect the rheology of the host rock. For example, if an intrusion is taking place near an area of magma storage, the crust heated by this presence could possess a different rheology, likely to be more ductile than elastic.

Also, the vegetable oil used as a magma analogue here has a single solidification temperature. Magma in nature will have a range of solidification temperature between its liquidus and solidus. 
This temperature range depends widely on its composition, which evolves as the magma solidifies. Likewise, the experimental temperature at the injection point $T_{i}$ was maintained constant during an experiment whereas magma temperature is likely to change during an intrusive event. In nature the thermal conditions $\theta$ are thus likely to change, which is not accounted for in these experiments. In the same way, $\phi$ remains constant during an experiment because $Q$ is maintained constant whereas natural magma fluxes are likely to wax and wane during the same injection of magma.

\section{Conclusions}

The purpose of this study was the quantification of the effects of solidification on the formation of sills by means of analogue laboratory experiments. They involved the injection of hot vegetable oil, a magma analogue that solidifies during its injection, in a layered colder solid gelatine, a host rock analogue. The injection temperature $T_{i}$ and the injection flux $Q$ were systematically varied between experiments. The experiments were carried out under dimensionless conditions (temperature $\theta$ and flux $\phi$ ) identical to those present in nature, and are correctly scaled geometrically, dynamically, kinematically, and thermally. The results are consistent with field observations and provide a means to explain why some dykes form sills where other dykes do not under similar geological conditions.

Several types of intrusions were observed: dykes stopping at the interface, dykes passing through the interface and sills. These different shapes demonstrate that contrary to isothermal experiments (no temperature effect able to block sill formation), a rigidity contrast between two layers is not a sufficient condition to create a sill. When solidification effects are significant (low $Q$ and $T_{i}$ slightly higher than $T_{s}$ ), the created dyke partially solidifies on the walls during its propagation, which prevents its piercing of the interface and propagation in the upper stiffer gelatine layer, or its spreading along the interface as a sill. When solidification effects are lower (range of medium $Q$ and $T_{i}$ higher than $T_{s}$ ), the feeder dyke can propagate as a sill by spreading at the interface between the two layers. When solidification effects are low (range of medium and high $Q$ and $T_{i}$ higher than $T_{s}$ ), the constant input of hot vegetable oil at the dyke tip allows it to pierce 
the interface and propagate in the upper layer of gelatine.

Thus, solidification effects restrict sill formation at an interface with a favourable rigidity contrast (upper layer stiffer than the lower one). Sill formation occurs only for a specific range of dimensionless temperatures $\theta$ and fluxes $\phi: \theta_{\min } \leq \theta \leq \theta_{\max }$, where $\theta_{\min }=0.0039 \phi+0.61$ and $\theta_{\max }=0.019 \phi+0.68$. The thermal conditions $(\theta)$ depend on injection temperature $T_{i}$, and dynamical conditions $(\phi)$ depend on injection flux $Q$ and rigidity contrast of the intruded solid. Therefore, in our experiments, sill formation along an interface depends on three critical parameters : the injection temperature $T_{i}$, the injection flux $Q$, and the rigidity of the rocks below this interface.

\section{Acknowledgements}

The authors would like to thank two anonymous reviewers whose comments have strengthened and improved the manuscript. L.C. was supported by a Fellowship from the French Ministry of Higher Education and Research (Ministre de l'Enseignement Suprieur et de la Recherche, MESR), and T.M. acknowledges support from a chaire mixte IRD-UBP. This is Laboratory of Excellence ClerVolc contribution no. XX.

\section{References}

\section{References}

Annen, C., Sparks, R. S. J., 2002. Effects of repetitive emplacement of basaltic intrusions on thermal evolution and melt generation in the crust. Earth and Planetary Science Letters 203, 937955.

Benn, K., Roest, W. R., Rochette, P., Evans, N. G., Pignotta, G. S., 1999. Geophysical and structural signatures of syntectonic batholith construction: the South Mountain Batholith, Meguma Terrane, Nova Scotia. Geophysical Journal International 136, 144-158. 
Bevington, P., Robinson, D. K., 2003. Data Reduction and Error Analysis for the Physical Sciences. McGraw-Hill, New York.

Bolchover, P., Lister, J. R., 1999. The effect of solidification on fluid-driven fracture, with application to bladed dykes. Proceedings of the Royal Society of London. Series A: Mathematical, Physical and Engineering Sciences 455 (1987), 2389-2409.

Burchardt, S., 2008. New insights into the mechanics of sill emplacement provided by field observations of the Njardvik Sill, Northeast Iceland. Journal of Volcanology and Geothermal Research 173, 280-288.

Cartwright, J., Hansen, D. M. 1., 2006. Magma transport through the crust via interconnected sill complexes. Geology 34 (11), 929-932.

Corry, C. E., 1988. Laccoliths; mechanics of emplacement and growth. Geological Society of America Special Papers 220, 1-114.

Crisp, J., 1952. The Use of Gelatin Models in Structural Analysis. Proceeding IB of the Institute of Mechanical Engineers 12, 580-604.

Delaney, P. T., Pollard, D. D., 1981. Deformation of host rocks and flow of magma during growth of minette dikes and breccia-bearing intrusions near Ship Rock, New Mexico. US Government Printing Office.

Galland, O., Cobbold, P. R., Hallot, E., de Bremond d'Ars, J., Delavaud, G., 2006. Use of vegetable oil and silica powder for scale modelling of magmatic intrusion in a deforming brittle crust. Earth and Planetary Science Letters 243 (3-4), 786-804.

Gudmundsson, A., 2011. Deflection of dykes into sills at discontinuities and magma-chamber formation. Tectonophysics 500 (1-4), 50-64.

Horsman, E., Morgan, S., de Saint-Blanquat, M., Habert, G., Nugent, A., Hunter, R. a., Tikoff, B., 2010. Emplacement and assembly of shallow intrusions from multiple magma pulses, Henry 
Mountains, Utah. Earth and Environmental Science Transactions of the Royal Society of Edinburgh 100, 117-132.

John, B. E., 1988. Structural reconstruction and zonation of a tilted mid-crustal magma chamber: The felsic Chemehuevi Mountains plutonic suite. Geology 16, 613-617.

Kavanagh, J. L., Menand, T., Daniels, K., 2013. Gelatine as a crustal analogue: Determining elastic properties for modelling magmatic intrusions. Tectonophysics 582, 101-111.

Kavanagh, J. L., Menand, T., Sparks, R. S. J., 2006. An experimental investigation of sill formation and propagation in layered elastic media. Earth and Planetary Science Letters 245 (3-4), 799813.

Kavanagh, J. L., Sparks, R. S. J., 2011. Insights of dyke emplacement mechanics from detailed 3D dyke thickness datasets. Journal of the Geological Society 168, 965-978.

Leuthold, J., Müntener, O., Baumgartner, L. P., Putlitz, B., Ovtcharova, M., Schaltegger, U., 2012. Time resolved construction of a bimodal laccolith (Torres del Paine, Patagonia). Earth and Planetary Science Letters 325-326, 85-92.

Lister, J. R., 1999. Fluid-mechinical models of the interaction between solidification and flow in dykes. Physics and chemistry of dykes, 115-124.

Maccaferri, F., Bonafede, M., Rivalta, E., 2010. A numerical model of dyke propagation in layered elastic media. Geophysical Journal International 180 (3), 1107-1123.

Macdonald, G. A., Finch, R. H., 1950. The June 1950 eruption of Mauna Loa, Part II. The Volcano Letter 509, 1-6.

Menand, T., 2008. The mechanics and dynamics of sills in layered elastic rocks and their implications for the growth of laccoliths and other igneous complexes. Earth and Planetary Science Letters 267, 93-99. 
Menand, T., 2011. Physical controls and depth of emplacement of igneous bodies: A review. Tectonophysics 500 (1-4), 11-19.

Menand, T., Daniels, K. A., Benghiat, P., 2010. Dyke propagation and sill formation in a compressive tectonic environment. Journal of Geophysical Research: Solid Earth (1978-2012) 115 (B8).

Miller, C. F., Furbish, D. J., Walker, B. a., Claiborne, L. L., Koteas, G. C., Bleick, H. a., Miller, J. S., 2011. Growth of plutons by incremental emplacement of sheets in crystal-rich host: Evidence from Miocene intrusions of the Colorado River region, Nevada, USA. Tectonophysics 500, 6577.

Muirhead, J. D., Airoldi, G., Rowland, J. V., White, J. D. L., 2012. Interconnected sills and inclined sheet intrusions control shallow magma transport in the Ferrar large igneous province, Antarctica. Geological Society of America Bulletin 124 (1-2), 162-180.

Parsons, T., Sleep, N. H., Thompson, G. A., 1992. Host rock rheology controls on the emplacement of tabular intrusions: Implications for underplating of extending crust. Tectonics 11 (6), 13481356.

Richards Jr, R., Mark, R., 1966. Gelatin models for photoelastic analysis of gravity structures. Experimental Mechanics 6 (1), 30-38.

Taisne, B., Jaupart, C., 2009. Dike propagation through layered rocks. Journal of Geophysical Research: Solid Earth (1978-2012) 114 (B9).

Taisne, B., Tait, S., 2009. Eruption versus intrusion? Arrest of propagation of constant volume, buoyant, liquid-filled cracks in an elastic, brittle host. Journal of Geophysical Research 114 (B6), B06202.

Taisne, B., Tait, S., 2011. Effect of solidification on a propagating dike. Journal of Geophysical Research 116 (B1), B01206. 
Thordarson, T., Self, S., 1993. The Laki (Skaftar Fires) and Grimsvötn eruptions in 1783-1785. Bulletin of Volcanology 55, 233-263.

Timoshenko, S. P., Goodier, J. N., 1970. Theory of Elasticity. McGraw-Hill, New York.

Traversa, P., Pinel, V., Grasso, J. R., 2010. A constant influx model for dike propagation : Implications for magma reservoir dynamics. Journal of Geophysical Research 115 (B1), 1-18.

White, R. S., Drew, J., Martens, H. R., Key, J., Soosalu, H., Jakobsdóttir, S. S., 2011. Dynamics of dyke intrusion in the mid-crust of Iceland. Earth and Planetary Science Letters 304 (3-4), $300-312$. 


\section{Captions of figures and tables}

FIGURE 1: Experimental apparatus.

The gelatine solid has two layers of different stiffness, to create a priori favourable conditions to form sills. Vegetable oil is heated with a bain-marie and injected at a constant rate with a peristaltic pump in the layered gelatine solid.

FIGURE 2: Experimental intrusions.

(A) Experimental dyke blocked at the interface, experiment 11, three-quarter view. (B) Experimental sill, experiment 1, side view. (C) Experimental dyke passing through the interface, experiment 2 , three-quarter view. The dyke takes a triangular shape above the interface.

FIGURE 3: Schematic diagram illustrating the formation of experimental intrusions.

(A) Initial circular dyke, front view. (B) The dyke stops at the interface between the two layers and propagation continues laterally beneath the interface, front view. (C), (D) and (E) are the final shapes of the three different intrusions observed in the experiments. (C) Final shape of the dyke stopping at the interface, front view. (D) The dyke fractures the gelatine at the interface and creates a sill, side view. (E) The dyke pierces the interface, propagates into the upper layer of gelatine and creates a dyke passing through the interface, front view. The dyke takes a triangular shape above the interface.

FIGURE 4: Morphologies of intrusions.

(A) Plumose structures on the feeder dyke, experiment 7, front view. (B) En-echelon segments at the upper tip of the dyke, experiment 14, top view. (C) Lobes on the side of the dyke, experiment 14, side view. (D) Smooth surface and asperity filled by gelatine on a sill, experiment 1, top view. (E) Discontinuities at the edge of the sill, experiment 5, side view.

FIGURE 5: Dimensionless temperature $\theta$ as a function of dimensionless flux $\phi$. 
Gray area shows natural ranges of values for $\theta$ and $\phi$ as defined in 2.5. Stars represent experiments where no propagation occured; squares are dykes blocked at the interface; disks are sills; triangles are dykes passing through the interface. Lines (a), (b) and (c) delimit the areas for each type of intrusions. The dashed line (a) is only qualitative whereas the continuous lines (b) and (c) can be determined reliably. See text for details.

FIGURE 6: Sill with its feeder dyke in the Henry Mountains, Utah, USA, modified from Menand (2011).

The view is from the East. The sill, its feeder dyke (both outlined by dashed white lines) and the intruded layered sandstone (continuous white lines) have all been rotated almost $90^{\circ}$. The feeder dyke crosses several similar interfaces before spreading as a sill.

TABLE 1: Behaviour of the dimensionless temperature $\theta$ and dimensionless flux $\phi$.

TABLE 2: Experimental data for investigation of sill formation.

$\theta$ is calculated from equation (4) with $T_{s}=31^{\circ} \mathrm{C} . \phi$ is calculated from equation (7) with $\Delta \rho=$ $100, g=9.81 \mathrm{~m} \cdot \mathrm{s}^{-1}, \kappa=1.4 \times 10^{-7} \mathrm{~m}^{2} . \mathrm{s}^{-1} . E$ of the lower gelatine layer is determined and calculated from equation (3). The uncertainties $\sigma_{\theta}$ and $\sigma_{\phi}$ were calculated according to the principles of the "Propagation of Errors" (Bevington and Robinson, 2003). 


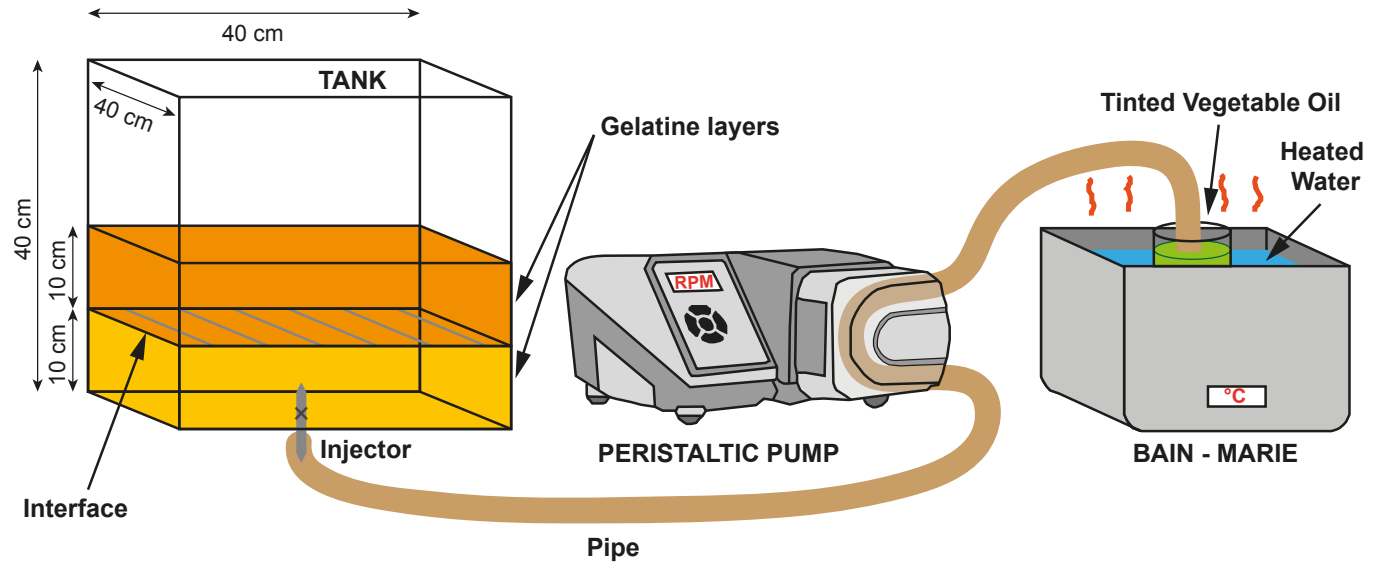

Figure 1: Experimental apparatus.

The gelatine solid has two layers of different stiffness, to create a priori favourable conditions to form sills. Vegetable oil is heated with a bain-marie and injected at a constant rate with a peristaltic pump in the layered gelatine solid. 


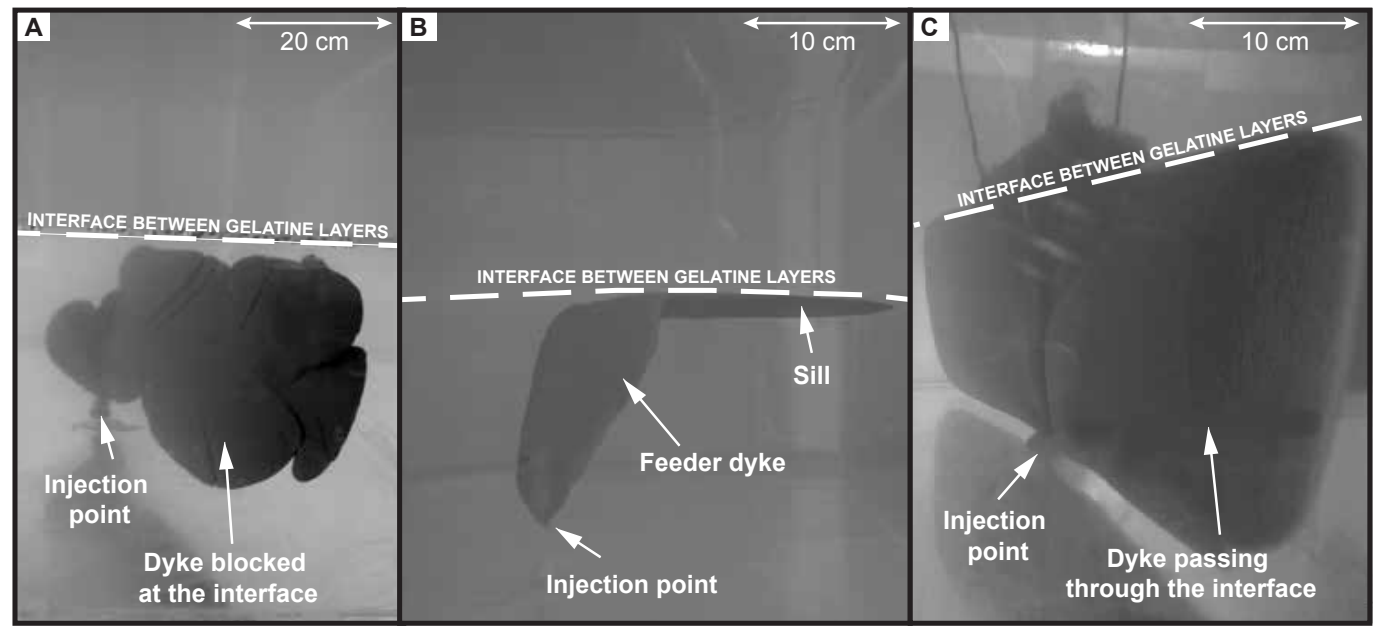

Figure 2: Experimental intrusions.

(A) Experimental dyke blocked at the interface, experiment 11, three-quarter view. (B) Experimental sill, experiment 1, side view. (C) Experimental dyke passing through the interface, experiment 2, three-quarter view. The dyke takes a triangular shape above the interface. 


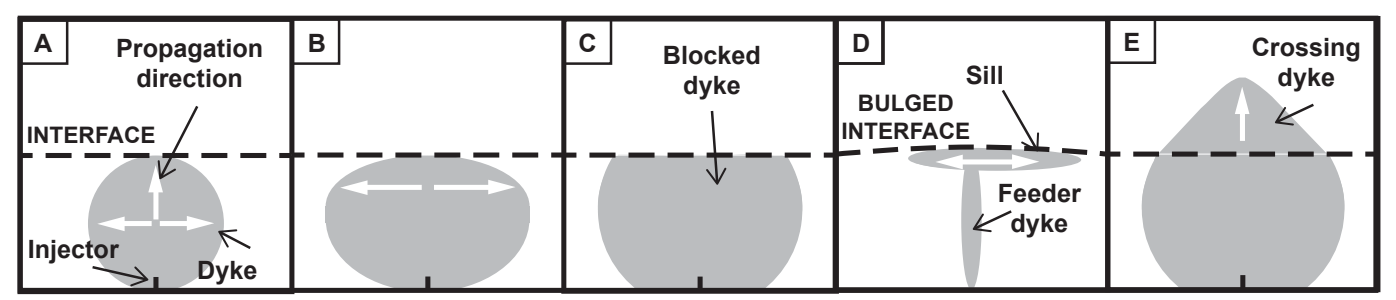

Figure 3: Schematic diagram illustrating the formation of experimental intrusions.

(A) Initial circular dyke, front view. (B) The dyke stops at the interface between the two layers and propagation continues laterally beneath the interface, front view. (C), (D) and (E) are the final shapes of the three different intrusions observed in the experiments. (C) Final shape of the dyke stopping at the interface, front view. (D) The dyke fractures the gelatine at the interface and creates a sill, side view. (E) The dyke pierces the interface, propagates into the upper layer of gelatine and creates a dyke passing through the interface, front view. The dyke takes a triangular shape above the interface. 


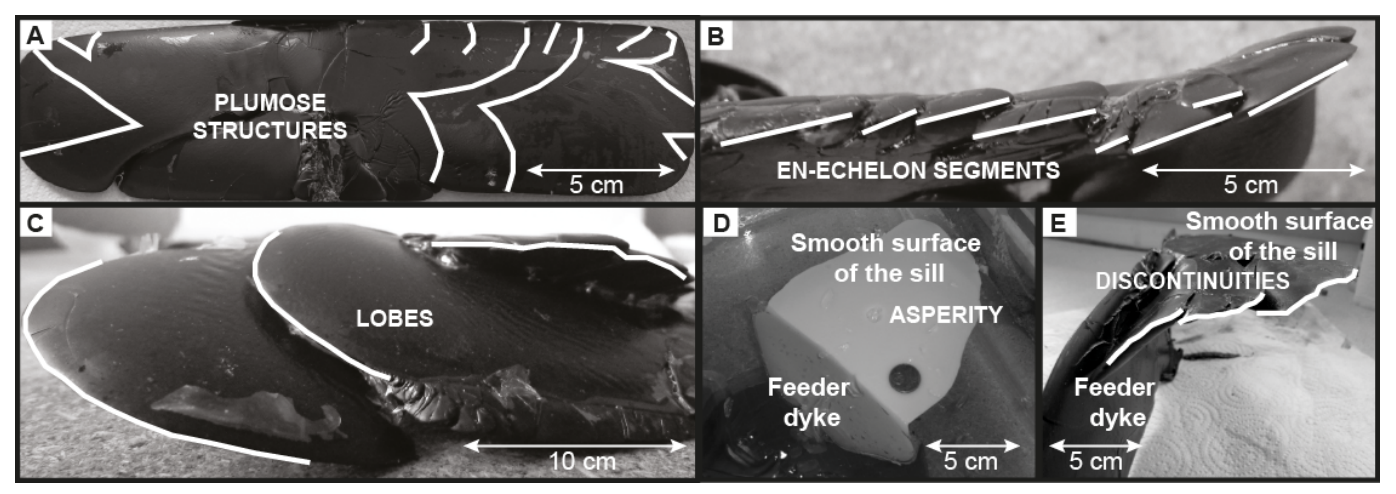

Figure 4: Morphologies of intrusions.

(A) Plumose structures on the feeder dyke, experiment 7, front view. (B) En-echelon segments at the upper tip of the dyke, experiment 14, top view. (C) Lobes on the side of the dyke, experiment 14, side view. (D) Smooth surface and asperity filled by gelatine on a sill, experiment 1 , top view. (E) Discontinuities at the edge of the sill, experiment 5 , side view. 


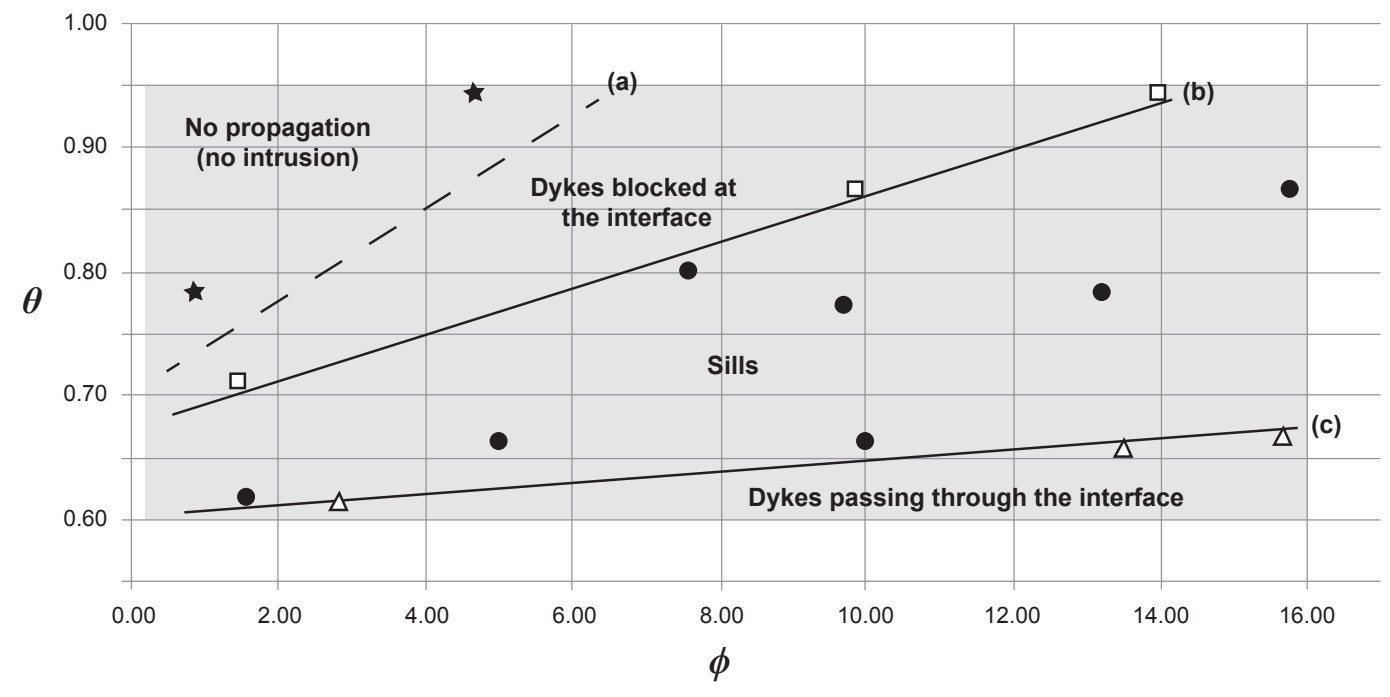

Figure 5: Dimensionless temperature $\theta$ as a function of dimensionless flux $\phi$.

Gray area shows natural ranges of values for $\theta$ and $\phi$ as defined in 2.5. Stars represent experiments where no propagation occured; squares are dykes blocked at the interface; disks are sills; triangles are dykes passing through the interface. Lines (a), (b) and (c) delimit the areas for each type of intrusions. The dashed line (a) is only qualitative whereas the continuous lines (b) and (c) can be determined reliably. See text for details. 


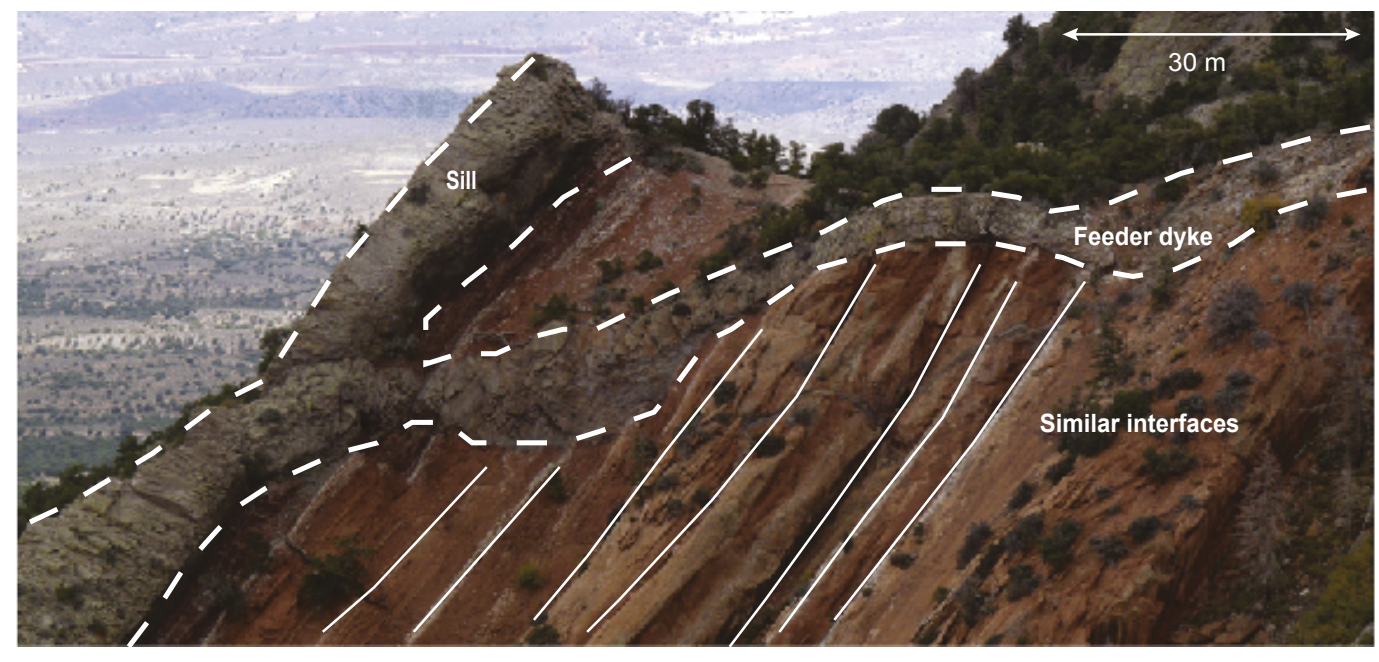

Figure 6: Sill with its feeder dyke in the Henry Mountains, Utah, USA, modified from Menand (2011).

The view is from the East. The sill, its feeder dyke (both outlined by dashed white lines) and the intruded layered sandstone (continuous white lines) have all been rotated almost $90^{\circ}$. The feeder dyke crosses several similar interfaces before spreading as a sill. 